\title{
Portulacaceae endémicas del Perú
}

\section{Blanca León ${ }^{1,2}$}

${ }^{1}$ Museo de Historia Natural, Av. Arenales 1256, Aptdo. 14-0434, Lima 14, Perú

2 Plant Resources Center, University of Texas at Austin, Austin TX 78712 EE.UU.

blanca.leon@mail.utexas.edu

\section{Resumen}

La familia Portulacaceae es reconocida en el Perú por presentar seis géneros y 26 especies (Brako \& Zarucchi, 1993), todas hierbas y/o subarbustos. En este trabajo reconocemos siete especies endémicas en tres géneros. Las especies endémicas provienen mayormente de la región Desierto Semicálido Tropical, entre los 100 y los $800 \mathrm{~m}$ de altitud. Se aplicaron las categorías y criterios de la UICN a tres especies. Aparentemente, ninguna de las especies endémicas se encuentra representada dentro del Sistema Nacional de Áreas Naturales Protegidas por el Estado.

Palabras claves: Portulacaceae, Perú, endemismo, plantas endémicas.

\section{Abstract}

The Portulacaceae are represented in Peru by six genera and 26 species (Brako \& Zarucchi, 1993), all herbs and subshrubs. Here we recognize seven endemic species in three genera. These endemic species come from mostly Subtropical Costal Desert, between 100 and 800 m elevation. We apply IUCN categories and criteria to three species. Apparently, none of these endemic species has been found in the Peruvian System of Protected Natural Areas.

Keywords: Portulacaceae, Peru, endemism, endemic plants.

\section{Calandrinia alba (Ruiz \& Pav.) DC.}

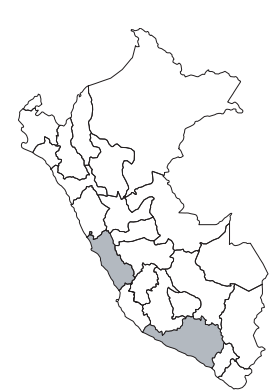

\section{DD}

Publicación: Prodr. 3: 359. 1828.

Colección tipo: H. Ruiz \& J. Pavón s.n. Herbarios: MA.

Nombre común: Desconocido Registro departamental: AR, LI. Regiones Ecológicas: DST; $300 — 800 \mathrm{~m}$. SINANPE: Sin registro.

Herbarios peruanos: Ninguno.

Observaciones: Hierba conocida de ambientes asociados a las neblinas de invierno. Las poblaciones conocidas se hallan dispersas en la costa del centro y sur del país. Se desconoce el estado de sus poblaciones.

\section{Calandrinia linomimeta Diels}

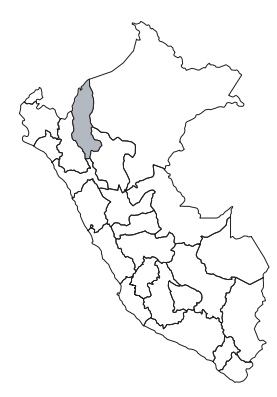

\section{DD}

Publicación: Bot. Jahrb. Syst. 37: 400. 1906.

Colección tipo: A. Weberbauer 4788

Herbarios: B.

Nombre común: Desconocido.

Registro departamental: AM.

Regiones Ecológicas: BS; $600 \mathrm{~m}$.

SINANPE: Sin registro.

Herbarios peruanos: Ninguno.

Observaciones: Especie subarbustiva, al parecer, sólo conocida de la cuenca del Marañón. No ha vuelto a ser recolectada desde 1905. Se desconoce el estado actual de sus poblaciones.

\section{Cistanthe lingulata (Ruiz \& Pav.) Hershkovitz}

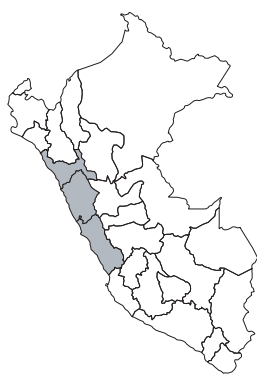

Publicación: Phytologia 70(3): 214. 1991. Colección tipo: J. Pavón s.n.

Herbarios: G.

Nombre común: Desconocido.

Registro departamental: AN, LI, LL.

Regiones Ecológicas: DST, BS; $280 \mathrm{~m}$.

SINANPE: Sin registro.

Herbarios peruanos: $\mathrm{HAO}(1)$.

Observaciones: Este taxón fue considerado por Brako \& Zarucchi (1993) como un endemismo; sin embargo, no ha sido posible evaluarlo, ni asignarle una categoría.

\section{Cistanthe paniculata (Ruiz \& Pav.) Carolin ex Hershkovitz}

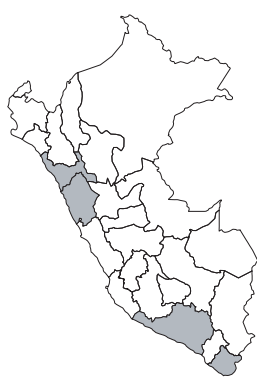

Publicación: Phytologia 70(3): 216. 1991. Colección tipo: H. Ruiz \& J. Pavón s.n. Herbarios:

Nombre común: Desconocido. Registro departamental: AN, AR, LI, LL, TA.

Regiones Ecológicas: DST; 300—550 m. SINANPE: Sin registro.

Herbarios peruanos: HAO (2).

Observaciones: Este taxón fue considerado por Brako \& Zarucchi (1993) como un endemismo; sin embargo, no ha sido posible evaluarlo, ni asignarle una categoría. 


\section{Cistanthe weberbaueri (Diels) Carolin ex Hershkovitz}

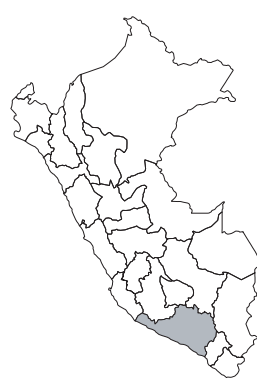

DD

Publicación: Phytologia 70(3): 218. 1991. Colección tipo: A. Weberbauer 1507 Herbarios:

Nombre común: Desconocido.

Registro departamental: AR.

Regiones Ecológicas: DST; $100 \mathrm{~m}$.

SINANPE: Sin registro.

Herbarios peruanos: Ninguno.

Observaciones: Especie herbácea, descrita de una planta recolectada a inicios del siglo XX, de laderas rocosas en la costa sur del país. Se desconoce el estado actual de sus poblaciones.

\section{Portulaca macbridei D. Legrand}

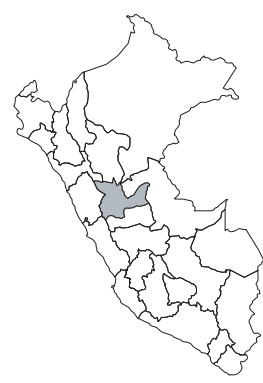

Publicación: Comun. Bot. Mus. Hist. Nat. Montevideo 2(22): 3, t. 1, f. 4. 1952.

Colección tipo: J.F. Macbride 3201

Herbarios: F, NY.

Nombre común: Desconocido.

Registro departamental: HU.

Regiones Ecológicas: MA; $2100 \mathrm{~m}$.

SINANPE: Sin registro.

Herbarios peruanos: Ninguno.

Observaciones: Este taxón fue considerado por Brako \& Zarucchi (1993) como un endemismo; sin embargo, no ha sido posible evaluarlo, ni asignarle una categoría.

\section{Portulaca nivea Poelln.}

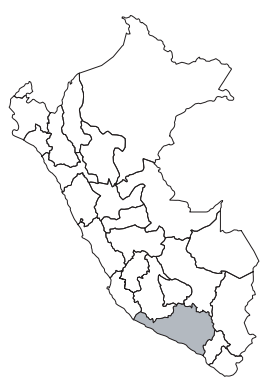

Publicación: Revista Sudamer. Bot. 7(68): 269. 1943.

Colección tipo: Desconocido. s.n.

Herbarios:

Nombre común: Desconocido.

Registro departamental: AR.

Regiones Ecológicas: DST; altitud desconocida.

SINANPE: Sin registro.

Herbarios peruanos: Ninguno.

Observaciones: Este taxón fue considerado por Brako \& Zarucchi (1993) como un endemismo; sin embargo, no ha sido posible evaluarlo, ni asignarle una categoría. 